\title{
The Effects of Viewing the Forest Landscape on Physiological and Psychological Status in Radiologists
}

\author{
Jung-Woo Shin ${ }^{1}$ and Jong-Hwan Choi $^{2 *}$ \\ ${ }^{1}$ Department of Forest Therapy, Chungbuk National University, Cheongju 28644, South Korea \\ ${ }^{2}$ Department of Physical Education, Chungbuk National University, Cheongju 28644, South Korea
}

\begin{abstract}
This study aimed to compare th effect of viewing forest and urban landscapes on the physiological responses and the psychological status of radiologists. An experiment was conducted among 10 healthy raiologists ( $\mathrm{n}=10,24 \pm 2.9$ years old). They were instructed to view forest and urban landscapes, and their HRV (Heart Rate Variability) was measured to assess their physiological responses, and POMS (Profile of Mood States), and SD (Semantic Differential) questionnaires were also conducted to assess their psychological status. The collected data were analyzed with Wilcoxon signed-rank test using the SPSS 21.0. The results showed that viewing the forest landscape stimulated the activity of the parasympathetic nervous system more than viewing the urban landscape, which reduced stress and stabilized the psychological status of participants, and that viewing the forest landscape also increased the levels of positive feelings among POMS and SD subscales. Therefore, it was concluded in this study that viewing forest landscapes can contribute to the reduction of stress, emotional stability, and positive psychological status of those who work in a closed space like radiologists.
\end{abstract}

Key words: emotion, heart rate variability, profile of mood states, semantic differential method, stress

\section{I . Introduction}

The transition from an analog society to a digital one has reduced the physical work load of radiologists, but instead required long hours of static postures and a high level of precision and concentration (Kim et al., 2010). Hospitals where radiologists work are labor-intensive work places where people in various types of occupation perform different types of work with professional skills (Kim et al., 1998). Radiologists in medical institutions have to work in a closed space to shield radiation with shielding walls or shielding materials according to Article 43 of the Regulations on Technical Standards for Radiation Safety Control, Etc.. Such special working environments and patterns cause various types of stress, act as a barrier to medical services provided by their team, and also affect their life and health (Jung and Son, 2005). Since radiologist have to do shift work, and thus have relatively only few hours of spare time, their health promotion scores are inevitably low and, thus, special attention needs to be paid to them (Ko et al.,

Received on March 10, 2017. Revised on April 20, 2017.

Accepted on May 22, 2017.

*Comesponding author: choij@chungbuk.ac.kr
2009). Working in a professional field, they face stress from their roles, working environments and job requirements, and institutional measures need to be provided to address the issue (Shim et al., 2012).

Various methods to relieve stress have been suggested, and many studies have been conducted on forest therapy, as a viable alternative to them. Forest therapy is defined, in Article 2 of the Forestry Culture and Recreation Act, as immunestrengthening and health-promoting activities, which utilize a variety of elements of the forest, including scents and scenic views. One of the notable studies on the effect of viewing the forest landscape in forest therapy is that by Ulrich Roger (1984). In the study, it was found that patients who were assigned to a room with a window overlooking nature after having a cholecystectomy were hospitalized for a shorter period of time, took a less amount of painkillers, and had less negative comments in nurses' notes and less complications than those who were assigned to a room with a window overlooking a wall. Laumann et al. (2001) conducted a survey among 238 students and they answered that natural landscapes were more restorative environmental elements than downtowns when imagining that they were living in a familiar high 
mountain or in downtown, Oslo. Brown et al. (2013) found that photos of natural landscapes were more effective to improve the restoration of the functions of the autonomic nervous system after having mental stress than those of urban environments. Li and Sullivan (2016) surveyed 94 students who were in classrooms without a window, with a window overlooking a wasteland, and with a window overlooking a green space, and found that those who were in a classroom with a window overlooking a green space showed a higher level of recovery from mental stress than others. Such studies were also conducted in Korea. Lee et al. (2009) reported that visual images of nature such as forest and water had a positive impact on the brainwave and emotion of human being, and Kim et al. (2012) suggested a technique for the management of forest landscapes to gain optimal therapeutic effects. Lee et al. (2014) presented 5 photos of negative and positive types each to 34 college students, and measured changes in their brainwave and attention-restoration ability by types of forest landscapes. The study found that photos of positive forest landscapes showed higher levels of $\alpha$ -wave and attention-restoration ability than negative ones. In other studies, forest therapy programs were found to have a positive impact on the restoration of the mental health of elementary students (Kim et al., 2013), and forest education programs for the youth were effective to improve psychological well-being and reduce stress (Cho et al., 2014). Forest therapy programs for nursing students had a positive impact on stress responses and spirituality (Song et al., 2014), and such programs for teachers were also found to have a positive impact on their job stress, fatigue and emotional states (Jo et al., 2015).

It is recommended to comprehensively analyze responses to assess stress levels, but it can be quantitatively assessed simply by testing the function of the autonomic nervous system, a main source of stress response, through the HRV (heart rate variability) of electrocardiograms (ECGs) (Park et al., 2007). Choi and No (2004) pointed out that the power spectral density analysis of the $\mathrm{HRV}$ is recognized as a practical and economical method in clinical settings, and introduced it as a method of quantifying the balance of the autonomic nervous system. Lee et al. (1994) pointed out that a normalized unit, that is, a relative value that compensates differences between individuals, is more useful in power spectral density analysis than an absolute value, since differences between individuals are larger than an absolute value. Jung et. al. (2013) also measured the effect of viewing forest landscapes on the physiological stability of normal persons using a normalized unit.

Donovan et al. (2013), however, pointed out that the patients in the study of Ulrich mentioned above hardly spent time in their room, which could be problematic. The issue can act as an unintended confounding variable because natural landscapes are directly or indirectly exposed to participants. In this study, 44 earlier studies on forest therapy published recently were reviewed. Out of them, 30 studies targeted normal persons, and 6 out of 11 studies published in 2014 were conducted among college students (Choi 2016). This shows that subjects of recent studies on forest therapy were groups that could be easily exposed to forest environments in daily life, and thus they are also not free from the issue pointed out by Donovan et al. (2013). Therefore, clinical experiments conducted among radiologists have an advantage of minimizing confounding variables as they spend most of their time in a closed space compared to other groups, and they are suitable to verify the effect of forest therapy as they face job stress due to high-level skills and shift work required in the job.

As shown above, studies on the effect of viewing forest landscapes have proven its effect on different age groups using various methods for a long time, but there is almost no study on its effect on radiologist who are relatively less exposed to forest environments. In this regard, this study aimed to compare the effect of viewing forest landscapes and urban landscapes on the physiological and psychological status of radiologists who are less exposed to forest environments.

\section{Research Methods}

\section{Subjects}

An experiment was conducted among 10 healthy radiologists (10 males, average age: $24 \pm 2.9$, height: $173 \pm 4$.9, weight: $73 \pm 7.2$ ). The average length of working experience as a radiologist was $3 \pm 0.4$ years, and 2 participants were an ordinary worker, and the rest 8 participants were shift workers including night shift workers. They were chosen among those who had no medical or family history of cardiovascular diseases. In addition, they were not allowed to drink alcohol, consume caffeine, and 
smoke for 8 hours prior to the experiment since such activities can affect the response of the cardiovascular system. They were also encouraged to have sufficient sleep the day before the experiment to minimize their fatigue on the day of the experiment. In the process of this experiment, the participants were provided with instructions on the experiment except the purpose of this study, and they signed the consent form for voluntary participation.

\section{Experi stimuli}

In this study, roof garden and ordinary roof environments were provided as experimental stimuli to assess the physiological and $\underline{s}$ of participants in forest and urban environments. Fig. 1 shows images of the experimental stimuli (Fig. 1). This experiment was conducted in $\mathrm{C}$ university hospital located in $\mathrm{C}$ city, and the roof garden on $\mathrm{C}$ university hospital was selected as the forest environment, and a place surrounded by walls on the rooftop of $\mathrm{C}$ university hospital as the urban environment. The vegetation of the roof garden is composed of natural trees-mostly oak trees (Quercus acutissima, Quercus aliena, Quercus serrata) —and their height was over $20 \mathrm{~m}$, and the average diameter of breast height, $25 \sim 30 \mathrm{~cm}$.

\section{Experimental design}

In order to analyze changes in the physiological and psychological statuss of radiologists after viewing forest and urban landscapes, participants viewed the landscape of the roof garden selected in this study, and their HRV (Hearth Rate Variability), POMS (Profile of Mood States), and SD (Semantic Differential) were measured. After that, participants viewed the landscape of the rooftop without a forest landscape. Changes before and after viewing the landscape were analyzed. The results of the HRV can show large differences between individuals in the balanced physiological state due to the antagonism of the autonomic nervous system, and thus it is not desirable to compare the results of the HRV (Kim, 2014) individually. In this study, changes in the HRV of the participants caused by the experimental stimuli were measured, viewing them as a group.

\section{Experimental tools}

1) Heart Rate Variability (HRV)

Heart rate variability (HRV) is widely used as an indicator of the activity of the autonomic nervous system, and physiological changes can be simply and noninvasively detected with the method. In this study, the normHF (Normalized High Frequency) and LF/HF (Lower Frequency/High Frequency) of the HRV were used, and normHF is known as an indicator of the activity of the parasympathetic nervous system, and LF/HF, as an indicator of the activity of the sympathetic nervous system. The HRV was measured using Canopy9 RSA of IEMBIO, a wired heart rate detector. This experiment was conducted between $7 \mathrm{am}$ and $12 \mathrm{pm}$ to avoid the interference of the circadian rhythm of heart rate, and the HRV of participants
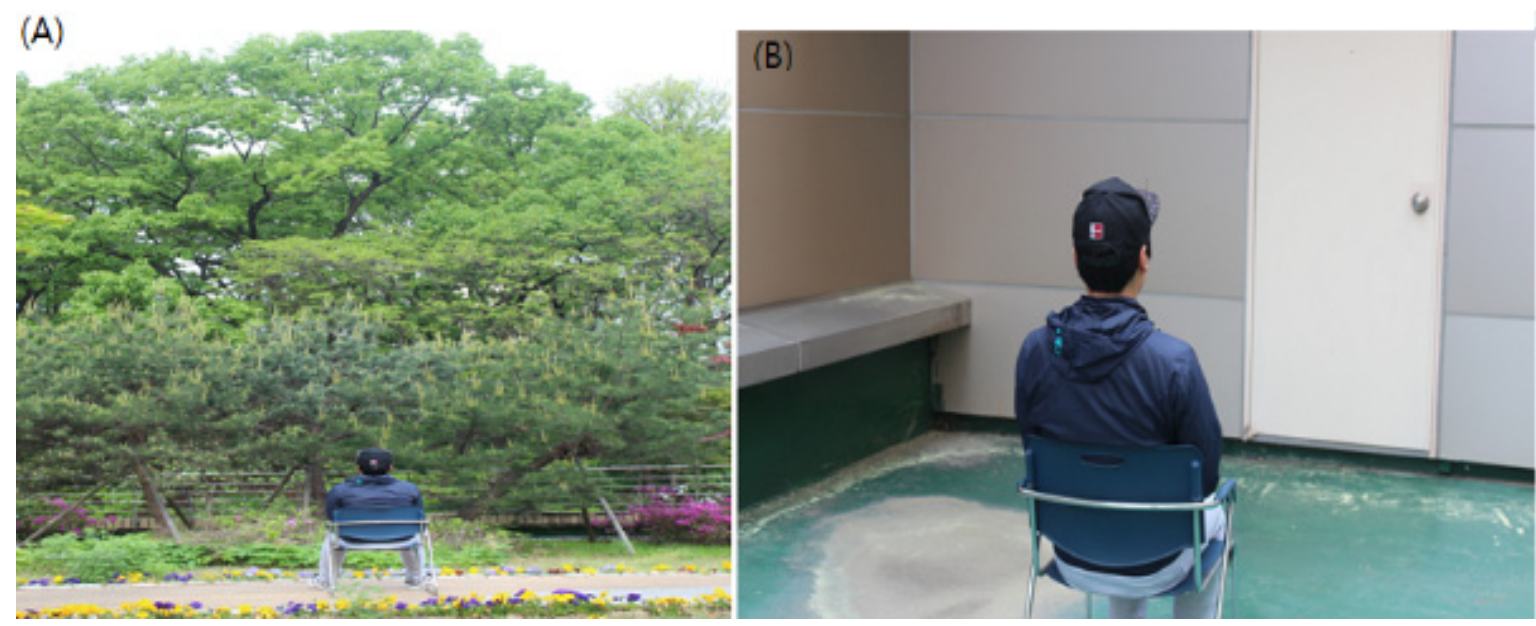

Fig. 1. Experimental stilmuli (A, forest area; $B$, urban area). 
was measured for 5 minutes while they were lying in a relaxed state (Kim, 2014).

\section{2) Profile of Mood States (POMS)}

The profile of mood states (POMS) is a scale used to assess changes in mood or emotional states caused by environments, and the impact of a simple therapeutic intervention can be easily measured with the POMS. The scale consists of 65 questions on participants' tension-anxiety, depression, angerhostility, vigor, fatigue and confusion (McNair et al., 1992), and they were used to assess the mood and emotional states of participants. A 5-point Likert scale (from 1 for "strongly disagree" to 5 for "strongly agree") was used, and participants are required to indicate how much they agree or disagree with each sentence. The total mood disturbance (TMD) is calculated by subtracting the score on vigor from the sum of the other five subscales (tension, depression, anger, fatigue and confusion). When this tool was developed, its reliability was Cronbach's $\alpha$ $=0.85$, and in this study, Cronbach's $\alpha=0.93$.

\section{3) Semantic Differential Method (SD)}

The semantic differential method (SD) is a scale used for assessing imagery that people form using emotional adjectives. In this study, 13-point scale questionnaires were developed using 3 emotions including, comfort, presence and stability. They were used to assess the mood and emotional states of participants (Osgood, 1964).

\section{Experimental methods}

Participants were instructed to sit in a comfortable chair in forest and urban environments and to view the surrounding landscapes. They were provided with brief instructions on the experiment prior to their participation, and they signed the consent form for participation.

Participants were randomly divided into two groups, 5 persons in one group. Those in the first group sat in a comfortable chair and viewed the forest environment for 15 minutes. After viewing the forest environment, their HRV was measured in a $63 \mathrm{~m}^{2}$-size closed room for 5 minutes to assess their physiological responses. After the measurement of the $\mathrm{HRV}$, they filled out the questionnaire in the same room. After that, they viewed the urban environment for 15 minutes, and the same assessment was performed in the room mentioned above. Those in the second group sat in a comfortable chair and viewed the urban environment first for 15 minutes. After viewing the urban environment, the same assessment procedure as the one for the first group, was carried out. After that, they viewed the forest environment for 15 minutes and the same assessment was repeated (Fig. 2). Changes in the assessment indicators after viewing each environment were used to compare the physiological responses of participants to the presented landscapes.

To measure their psychological status, subjective questionnaires of the POMS and SD were provided after measuring the HRV.

To minimize exogenous variables, other people except one experiment assistant and one participant were not allowed to access the locations for the experiment and measurement. The location for the experiment was on the third floor, and that for the measurement was within one minute distance from that for the experiment on the same floor. The temperature $\left(26^{\circ} \mathrm{C}\right)$, humidity (25\%), and illumination intensity (281 Lux) at the location for the measurement were maintained steady.

\section{Data analysis}

All the statistical analyses in this study were performed

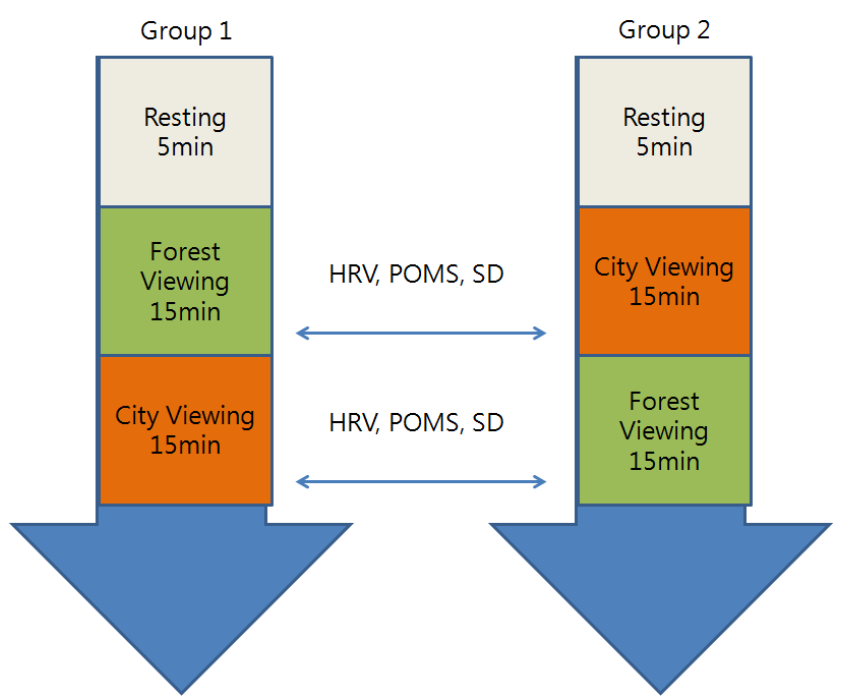

Fig. 2. Experimental protocol.

$H R V=h e a r t$ rate variability; POMS=profile of mood states; $S D=S e m a n t i c$ differential method. 
using SPSS 21.0 (SPSS, IBM Company, USA). The Wilcoxon signed-rank test was performed on the collected data in this experiment to identify the effect of forest and urban environments on the physiological and psychological status of radiologists, and changes in the data after viewing the forest environment and the urban environment were compared. Its statistical significance level was set to be $p<.05$.

\section{Results}

To compare the physiological and psychological status of radiologists in different environments, they were instructed to view forest and urban environments.

\section{Physiological responses}

The analyzed results of the HRV are as shown in Fig. 3 and 4. The value of normHF, an indicator of the activity of the parasympathetic nervous system, was $50.2 \pm 16.5 \mathrm{nu}$ after viewing

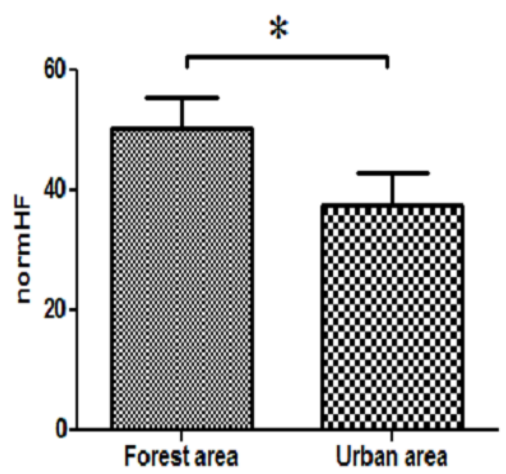

Fig. 3. Average normHF for forest area \& urban area normHF; normative high frequency. ${ }^{*} p<.05$.

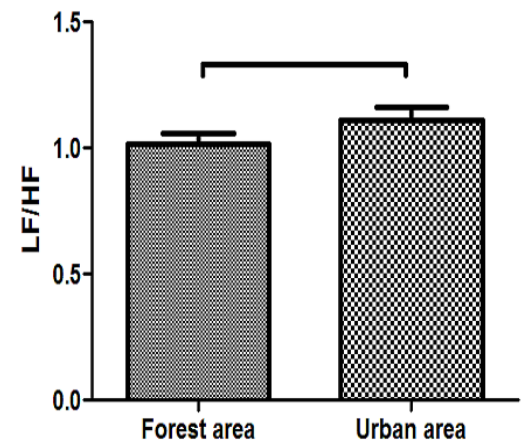

Fig. 4. Average LF/HF for forest area \& urban area LF/HF; lower frequency/high frequency. ${ }^{*} p<.05$ the forest landscape, and $37.5 \pm 17 \mathrm{nu}$ after viewing the urban landscape. The value after viewing the forest landscape was 34\% higher than that after viewing the urban landscape, which was statistically significant $(Z=-2.09, p=.037)$. The value of $\mathrm{LF} / \mathrm{HF}$, an indicator of the activity of the sympathetic nervous system, was $1.0 \pm 0.14$ after viewing the forest landscape, and $1.1 \pm 0.16$ after viewing the urban landscape, showing no statistically significant difference $(\mathrm{Z}=--1.581, p=.114)$.

\section{Psychological responses (POMS \& SD)}

The analyzed results of the POMS are as shown in Fig. 5. The POMS is a subjective assessment scale to measure 6 different psychological states including tension-anxiety, depression, anger-hostility, fatigue, confusion and vigor, and 5 subscales except vigor showed statistically significant differences. The score of tension-anxiety after viewing the forest landscape was $7 \pm 1.8$, statistically significantly lower than the score measured after viewing the urban landscape (10.8 \pm 2.1$)(Z=-2.554, p=$ .011). The score of depression after viewing the forest landscape was $5.6 \pm 2.1$, which was also statistically significantly lower than the score measured after viewing the urban landscape (9.5 \pm 2.7$)(\mathrm{Z}=-2.81, p=.005)$. The score of anger-hostility after viewing the forest landscape was $3.6 \pm 1.5$, statistically significantly lower than the score measured after viewing the urban

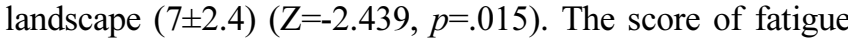
after viewing the forest landscape was $8 \pm 1.7$, which was also statistically significantly lower than the score measured after viewing the urban landscape $(10.3 \pm 1.7)(\mathrm{Z}=-2.606, p=.018)$. The score of confusion after viewing the forest landscape was (5.4 \pm 1$)$, statistically significantly lower than the score measured after viewing the urban landscape $(7.8 \pm 1.5)(\mathrm{Z}=-2.155, p=.031)$.

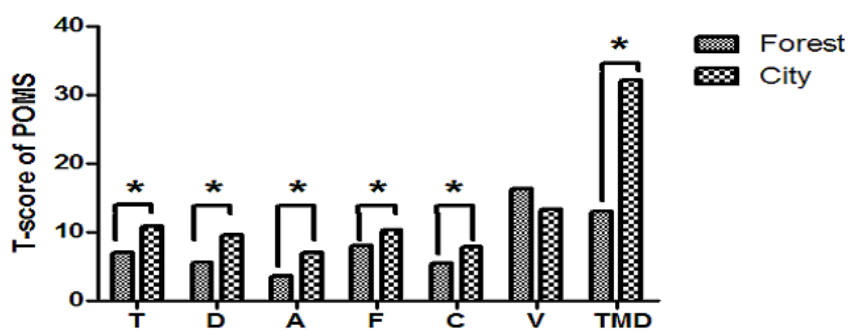

Fig. 5. Average subjective rating score (POMS) of six and total factors. $T=$ tension-anxiety; $\quad \mathrm{D}=$ depression; $\quad \mathrm{A}=$ =anger-hostility; $\quad \mathrm{F}=$ fatigue; $\mathrm{C}=$ confusion; $\mathrm{V}=$ vigor; $\mathrm{TMD}=$ total mood disturbance. ${ }^{*} p<.05$. 
The subscale of vigor scored $16.3 \pm 1.6$ after viewing the forest landscape, and the score was higher than the score measured after viewing the urban landscape (13.3 \pm 1.5$)$, but did not show any statistical significance $(\mathrm{Z}=-1.362, p=.173)$. Thus, the score of the total mood disturbance (TMD) that reflect all the six psychological states was $13 \pm 8.7$ after viewing the forest landscape, which was also statistically significantly lower than the score calculated after viewing the urban landscape (32.1 \pm 9.5$)$ $(\mathrm{Z}=-2.666, p=.008)$.

Meanwhile, the analyzed results of the SD are as shown in Fig. 6. The SD is a subjective assessment scale to measure 3 states including comfort, presence and stability. The subscales of comfort and presence showed statistically significant differences. The score of comfort was $9.7 \pm 0.6$ after viewing the forest landscape, statistically significantly higher than the score measured after viewing the urban landscape (7.2 \pm 0.8$)(\mathrm{Z}=$ $-2.153, p=.031)$. The score of presence was $8 \pm 0.6$ after viewing the forest landscape, which was also statistically significantly higher than the score measured after viewing the urban landscape $(6.7 \pm 0.5)(Z=-2.456, p=.014)$. However, the score of stability was $7.6 \pm 0.6$ after viewing the forest landscape, and the score was lower than the score measured after viewing the urban landscape $(8.1 \pm 0.5)$, but did not show any statistical significance $(\mathrm{Z}=-1.186, p=.236)$.

\section{Discussion}

The purpose of this study was to compare the effect of viewing forest and urban landscapes on the physiological responses and the psychological status of radiologists. To do so, their physiological and psychological status were assessed after viewing forest and urban landscapes. The HRV was utilized to assess their physiological responses, and the subjective questionnaires of the POMS and SD were conducted to assess their psychological status.

First, the results of the assessment of physiological responses showed that the HF values after viewing the forest landscape was higher than those after viewing the urban landscape. Other studies also reported that the values of $\mathrm{HF}$ after viewing forest landscapes were higher than those after viewing urban landscapes (Park et al., 2010, Lee et al., 2011, Song et al., 2015, Eom et al., 2015). However, in a study that was conducted among 9 adults who were instructed to view forest and urban landscapes in autumn for 15 minutes (Jung et al., 2013), the values of normHF after viewing forest landscapes were statistically significantly higher than those after viewing urban landscapes, but the values of $\mathrm{LF} /(\mathrm{LF}+\mathrm{HF})$, an indicator of the activity of the sympathetic nervous system, were statistically significantly low. On the contrary to this result, there was no statistically significant difference in the values of LF/HF in this study. The results of a study on the effect of viewing a vase of roses on office workers (Ikei et al., 2014) also showed a statistically significant difference in the value of $\mathrm{HF}$, an indicator of the activity of the parasympathetic nervous system, which was increased by $21 \%$, but no statistically significant difference in the value of LF/HF. The absolute value of HF in the study mentioned above and the relative value of normHF in this study showed statistically significant differences, but there was no significant difference in the value of LF/HF, which is attributable to the fact that there were not enough forests in forest environments in both studies. Therefore, since the autonomic nervous system controls the physiological balance
(A)

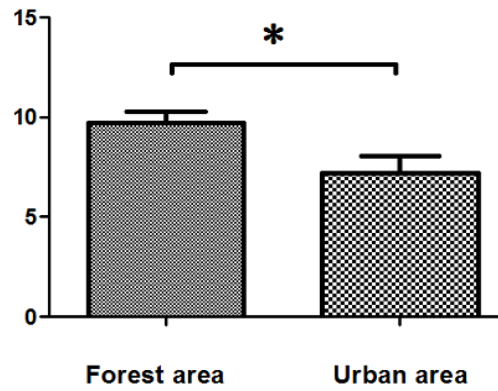

(B)

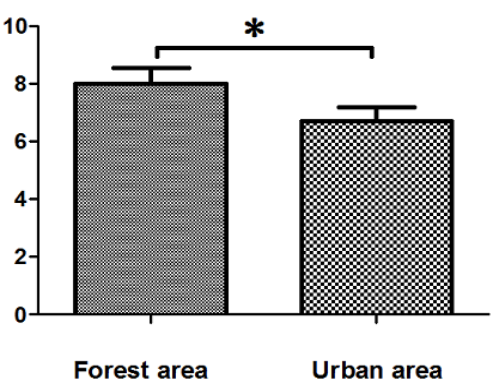

Fig. 6. Average subjective rating score. $A=$ Comfort; $B=$ Presence; $C=$ Stability. ${ }^{*} p<.05$.
(C)

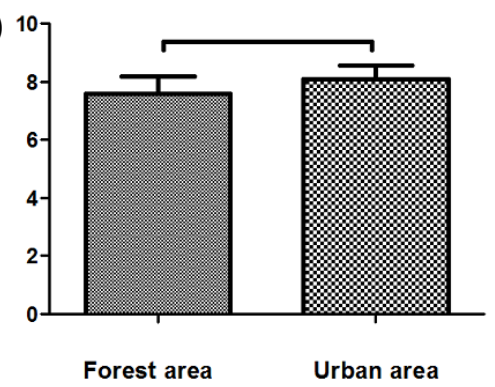


of bodies with interaction, viewing forest landscapes seems to activate the parasympathetic nervous system, but suppress the sympathetic nervous system.

Second, the results of the assessment of psychological status showed that the scores of negative feelings in the POMS decreased. The scores of tension, anger, fatigue and confusion after viewing the forest landscape were lower, but the scores of vigor were higher than after viewing the urban landscape. Thus, the total mood disturbance (TMD) was reduced. These results in this study were consistent with those of earlier studies that reported that viewing forest landscapes decreased the levels of tension, anger, fatigue, and confusion, but increased the level of vigor compared to the levels after viewing urban landscapes, thus reducing the level of the total mood disturbance (TMD) (Park et al., 2010, Lee et al., 2011). Park et al. (2010) pointed out that lower illumination intensity and humidity, and higher air pressure in forests reduced the levels of anger, fatigue and depression when viewing forest landscapes. However, Song et al. (2015) reported that there was no statistically significant difference in the POMS between forest and urban landscapes. Eom et al. (2015) said that there was a statistically significant increase only in the TMD after viewing valleys and forest roads compared to after viewing urban landscapes. Considering that both the two studies were conducted among college students by providing forest and lake landscapes, such differences can be attributable to the fact that subjects in the studies are more likely exposed to forest and lake environments.

Third, viewing forest landscapes was more effective for the subscales of comfort and stability in the SD, which was also consistent with the results of earlier studies that found that the group of people who viewed forest landscapes showed statistically significant differences in the levels of comfort and presence compared to the group of people who viewed urban landscapes (Lee et al., 2011, Jung et al., 2013, Eom et al., 2015, Song et al., 2015). In terms of the subscale of stability, however, the group of people who viewed forest groups in the earlier studies showed a higher level of stability than the group of people who viewed urban landscapes, but there was no significant difference in the two groups in this study. These results seems to be highly related to the findings of a study that pointed out that differences in the temperature between forest and urban areas, and forests themselves can increase the levels of comfort and refreshment (Tsunetsugu et al., 2007). Meanwhile, the reason why there was no significant difference in some subscales between the two groups was found through an indepth interview with individual participants after the experiment, and the reason seems to be a short period of time allowed for viewing landscapes. If participants are allowed to have enough time to admire landscapes, viewing forest landscapes will demonstrate a more positive impact on the psychological status of participants in the subscales of stability as well as comfort and presence than viewing urban landscapes. There are also some limitations in this study. Viewing forest landscapes had a positive impact on the physiological and psychological status of radiologists, but there were not enough forests since this study was conducted in a roof garden in a hospital. Active activities such as hands-on activities, and staying in forests for long hours were not considered in this study. Thus, it will be necessary to conduct follow-up studies on the effect of dense forests and active activities, targeting people like radiologists who work in a closed space. Despite those limitations, this study is still meaningful in the way that it was the first attempt to conduct a study on the stress of a group of people who were less exposed to forests unlike other subjects in earlier studies, and that the subjects of this study can be extended not only to those who have a high level of stress but also to those who are less exposed to forests or unable to participate in forest therapy.

\section{Conclusions}

This study aimed to compare the effect of viewing forest and urban landscapes on the physiological responses and the psychological status of radiologists. An experiment was conducted among 10 healthy radiologists $(n=10,24 \pm 2.9$ years old). They were instructed to view forest and urban landscapes, and their HRV (Heart Rate Variability) was measured to assess their physiological responses, and POMS (Profile of Mood States), and SD (Semantic Differential) questionnaires were also conducted to assess their psychological status. The results showed that viewing the forest landscape stimulated the activity of the parasympathetic nervous system more than viewing the urban landscape, which reduced stress and stabilized the psychological status of participants, and that viewing the forest landscape also increased the levels of positive feelings among 
POMS and SD subscales. Therefore, it was concluded in this study that viewing forest landscapes can contribute to the reduction of stress, emotional stability, and positive psychological status of those who work in a closed space like radiologists.

\section{References}

Brown, D.K., J.L. Barton, and V.F. Gladwell. 2013. Viewing nature scenes positively affects recovery of autonomic function following acute-mental stress. Environ. Sci.Technol. 47(11):5562-5569. DOI: $10.1021 / \mathrm{es} 305019 \mathrm{p}$

Cho, Y.M., D.J. Kim, P.S. Yeoun, H.K. Kwon, H.S. Cho, and J.M. Lee. 2014. The influence of a seasonal forest education program on psychological well-being and stress of adolescents. J. Korean Inst. For. Recreat. 18(2):59-69.

Choi, B.M., and G.J. No. 2004. Heart rate variability, HRV. Intraven. Anesth. 8:45-86.

Choi, M.H. 2016. Comparative review of forest healing and horticultural therapy literatures in korea. MS thesis, Kookmin Univ., Seoul, Korea.

Donovan, G.H., D.T. Butry, Y.L. Michael, J.P. Prestemon, A.M. Liebhold, D. Gatziolis, and M.Y. Mao. 2013. The relationship between trees and human health: evidence from the spread of the emerald ash borer. American journal of preventive medicine. 44(2):139-145. DOI: $10.1016 /$ j.amepre.2012.09.066

Eom, P.D. and M.C. Hwang. 2015. Effects of viewing environments of valley, forest road, and city on emotional state based on autonomic nervous system. J. Korean Inst. For. Recreat. 19(4): $1-12$.

Ikei, H., M. Komatsu, C. Song, E. Himoro, and Y. Miyazaki. 2014. The physiological and psychological relaxing effects of viewing rose flowers in office workers. J. Physiol. Anthropol. 33(1):6. DOI: 10.1186/1880-6805-33-6

Jo, M.N., C.S. Shin, P.S. Yeoun, and J.Y. Kim. 2015. The effects of the forest healing program according to job-stress, fatigue, mood state of the elementary school teachers. 2015. Proc. J. Kor. Institute of Forest Recreation. 2015: 408.

Jung, D.W., Y.H. Choi, K.W. Kim, C.W. Kwon, H.J. Lim, and B.J. Park. 2013. Psychological and physiological effects of viewing forest landscape in autumn season. Proc. J. Korean For. Soc. 2013: 1107-1109.

Jung, H.R. and B.S. Son. 2005. The analysis of stress levels of radiological technologists in genera hospitals according to their regional working envrionments. J Environ. Sci. Int. 14(4):435444. DOI: $10.5322 / J E S .2005 .14 .4 .435$

Kim, D.S. 2014. Forest therapy instructor training textbooks level 2. Retrieved from https://www.forest.go.kr/newkfsweb/cmm/fms/ BoardFileDown.do?atchFileId=FILE_000000000456574\&file $\mathrm{Sn}=0 \&$ dwldHistYn $=$ N\&bbsId $=$ BBSMSTR $1437 \& \mathrm{fn}=\% \mathrm{EC} \% 8$ $2 \% \mathrm{~B} 0 \% \mathrm{~EB} \% \mathrm{~A} 6 \% \mathrm{BC} \% \mathrm{EC} \% \mathrm{~B} 9 \% 98 \% \mathrm{EC} \% 9 \mathrm{C} \% \mathrm{~A} 0 \% \mathrm{EC} \% \mathrm{~A} 7$ $\% 80 \% \mathrm{~EB} \% 8 \mathrm{~F} \% 84 \% \mathrm{EC} \% 82 \% \mathrm{AC}(2 \% \mathrm{EA} \% \mathrm{~B} 8 \% 89)$.pdf. pp. 102.
Kim, J.S., S.J. Kim, H.J. Lee, J.E. Kim, H.J. Kim, I.I. Han, and Y.S. Joo. 2010. The study on risk factors analysis and improvement of VDT syndrome in nuclear medicine. Korean J. Nucl. Med. Technol. 14(1):61-66.

Kim, J.Y., C.S. Shin, P.S. Yeoun, J.Y. Lee, M.R. Kim, J.K. Kim, and Y.H. Yoo. 2013. Forest healing program impact on the mental health recovery of elementary school students. JJ. Korean Inst. For. Recreat. 17(4):69-81.

Kim, K.W., Y.H. Lee, and D.J. Kang. 2012. Forest management methods for enhancement of therapeutic effect. Proc. J. Korean For. Soc. 2012:89-92.

Kim, S.H., I.H. Bae, M.S. Lee, and Y.D. Kim. 1998. Study on job stress and job satisfaction of radiological technologists working general hospital. J. Korean Radiol. Technol. Association. 24(2):178-188.

Ko, J.K., D.M. Kwon, and Y.H. Kang. 2009. Analysis of influencing factors related to health promotion behavior in hospital radiological technologists. J. Korean Soc. Radiol. Technol. 32(4):381-391.

Laumann, K., T. Gärling, and K.M. Stormark. 2001. Rating scale measures of restorative components of environments. J. Environ. Psychol. 21(1): 31-44. DOI: 10.1006/jevp.2000.0179

Lee, J.H., W.S. Shin, P.S. Yeoun, and R.H. Yoo. 2009. The influence of forest scenes on psychophysiolosical responses. J. Korean For. Soc. 98(1):88-93.

Lee, J.Y., K.T. Park, M.S. Lee, B.J. Park, J.H. Ku, J.W. Lee, K.O. Oh, K.W. An, and Y. Miyazaki. 2011. Evidence-based field research on health benefits of urban green area. J. Korean Inst. Landsc. Archit. 39(5):111-118.

Lee, T.I., K.W. Choi, Y.J. Kim, D.G. Shin, Y.J. Kim, B.S. Sim, H.W. Lee, and K.H. Lee. 1994. Effects of stress on cardiovascular autonomic nervous activity in recovering myocardial infarction patients and normal controls measured by power spectral analysis. Korean. Circ. J. 24(1):24-37.

Lee, Y.H., C.W. Park, and J.J. Kim. 2014. Effects of visual stimulus with forest scenery types on psychological and physiological status of human. J. Korean Soc. People Plants Environ. 17(1): 65-71. DOI: 10.11628/ksppe.2014.17.1.065

$\mathrm{Li}$, D. and W.C. Sullivan. 2016. Impact of views to school landscapes on recovery from stress and mental fatigue. Landsc. Urban Plan. 148: 149-158. DOI: 10.1016/j.landurbplan.2015.12.015

McNair, D. M., L. F. Droppleman, and M. Lorr. 1992. Edits manual for the profile of mood states: POMS. Edits.

Osgood, C.E. 1964. Semantic differential technique in the comparative study of cultures, Am. Anthropol. 66(3):171-200. DOI: 10.1525/ aa.1964.66.3.02a00880

Park, B.J., Y. Ysunetsugu, T. Kasetani, T. Kagawa, and Y. Miyazaki. 2010. The physiological effects of shinrin-yoku (taking in the forest atmosphere or forest bathing): evidence from field experiments in 24 forests across japan. Environ. Health Prev. Med. 15(1):18-26. DOI: 10.1007/s12199-009-0086-9

Park, B.J., J.N. Ka, M.S. Lee, S.A. Kim, M.W. Park, Y.H. Choi, D.W Jung, C.W. Kwon, D.G. Park, S.K., and D.S. Kim. 2007. Relationship between physiological response and salivary cortisol level to life stress. J. Ergon. Soc. Korea 26(1):11-18. DOI: 10.5143/ 
JESK.2007.26.1.011

Shim, J.G., H.R. Jung, and I.K. You. 2012. Research of job satisfaction in radiation therapy technologist. J. Korea Contents Assoc. 12(8): 224-232. DOI: 10.5392/JKCA.2012.12.08.224

Song, C.R., J.Y. Lee, H. Ikei, T. Kagawa, Y. Miyazaki, and B.J. P. 2015. Physiological and psychological effects of walking around and viewing a lake in a forest environment. J. Korean For. Soc. 104(1):140-149. DOI: 10.14578/jkfs.2015.104.1.140

Song, J.H., J.K. Cha, C.Y. Lee, Y.S. Choi, and P.S. Yeon. 2014. Effects of forest healing program on stress response and spirituality in female nursing college students and there experience. J. Korean Inst. For. Recreat. 18(1):109-125.

Tsunetsugu, Y., B.J. Park, H. Ishii, H. Hirano, T. Kagawa, and Y. Miyazaki. 2007. Physiological effects of shinrin-yoku (taking in the atmosphere of the forest) in an old-growth broadleaf forest in yamagata prefecture, Japan. J. Physiol. Anthropol. 26(2):135-142. DOI: $10.2114 /$ jpa2.26.135

Ulrich, R.S. 1984. View through a window may influence recovery from surgery. Science. 224:420-421. DOI: 10.1126/science.6143402 